\title{
Estudos de caracterização dos novos depósitos de argilas esmectíticas do município de Sossego, PB
}

\author{
(Characterization studies of new deposits of smectite clays \\ from Sossego district, PB, Brazil)
}

\author{
I. D. S. Pereira, I. A. Silva, J. M. Cartaxo, R. R. Menezes, L. N. L. Santana, G. A. Neves, H. C. Ferreira \\ UFCG - CCT - UAEMa, R. Aprígio Veloso 882,Campina Grande, PB 58429-900 \\ Julianamelo25@gmail.com,gelmires@dema.ufcg.edu.br.lisiane@dema.ufcg.edu.br,heber@dema.ufcg.edu.br
}

\begin{abstract}
Resumo
As principais reservas de argilas bentonitas no Brasil encontram-se nos estados de S. Paulo, Bahia, Piauí e Paraíba, sendo este ultimo como maior produtor nacional. Os grandes depósitos dessas argilas provem do município de Boa Vista, PB, que atualmente encontra-se em fase exaustão devido à exploração desordenada. Outros novos depósitos foram descobertos nos municípios de Cubati, PB e Pedra Lavrada, PB, sendo o mais recente o município de Sossego, PB, fato que pode representar uma interessante alternativa tecnológica à futura escassez das argilas bentoníticas na Paraíba, ampliação da produção mineral na região e consolidação do estado como o maior produtor do país. Este trabalho tem por objetivo estudar as argilas esmectíticas do município de Sossego, PB. Inicialmente as amostras foram submetidas a uma caracterização física, química e mineralógica através das seguintes técnicas: análise granulometrica por difração a laser, composição química por fluorescência de raios X, difração de raios X, análise térmica diferencial e termogravimetrica. Após os ensaios de caracterização foram determinadas as propriedades reológicas com base na norma da Petrobrás para fluidos base água. Os resultados evidenciaram que as argilas apresentaram em sua composição mineralógica esmectita, caulinita, feldspato e quartzo. Em relação às propriedades reológicas, os resultados foram promissores para algumas amostras para uso em fluidos de perfuração.
\end{abstract}

Palavras-chave: bentonitas, reologia, caracterização.

\begin{abstract}
The main reserves of bentonite clays in Brazil are located in the states of S. Paulo, Bahia, Piaui and Paraiba, the latter being as a major national producer. Large deposits of these clays are found in Boa Vista, PB, which is currently in depletion phase due to uncontrolled exploitation. Other deposits were discovered in Districts of Cubati, and Pedra Lavrada, PB, and recently in the Sossego district, PB, Brazil, was discovered a new deposit which may represent an interesting alternative technology to future shortages of Paraiba bentonite clays, expansion of mineral production in region and consolidation of the state as the largest producer in the country. This work aims to study the smectite clays from Sossego District, PB. Initially the samples were submitted to characterize physical, chemical and mineralogical through the following techniques: granulometric analysis by laser diffraction, chemical composition by X-ray fluorescence, X-ray diffraction, thermal differential and thermogravimetric analysis. After those tests, were determined the rheological properties, based on standard Petrobras, for drilling water based fluids. The results showed that mineralogical composition clays were smectite, kaolinite, feldspar and quartz. The rheological properties results indicated that some samples were promising for use in drilling fluids.
\end{abstract}

Keywords: bentonite, rheology, characterization.

\section{INTRODUÇÃO}

O estado da Paraíba é o maior fornecedor nacional de esmectítas policatiônicas e sódicas. Os jazimentos situados em Boa Vista, PB, já apresentam sinais de exaustão. Como resultados de pesquisas de novas ocorrências foram descobertos os jazimentos nos munícipios Cubatí e Pedra Lavrada e mais recentemente foi descoberto um depósito no município de Sossego, PB, objetos de diversas pesquisas em andamento. A incessante busca por novos jazimentos decorre da grande importância industrial das esmectítas sendo de domínio publico que essas argilas, isoladamente, apresentam mais usos industriais que todos os tipos de argilas reunidas. Recentemente as argilas esmectitícas assumiram novos destaques pelo desenvolvimento de novos usos industriais visando proteger e remediar problemas ambientais, também merece destaque o desenvolvimento de novos materiais feitos sob medida (taylormade) [1,2]. A versatilidade dessas argilas deve-se dentre de outros fatores, pela sua fina granulometria com área especifica teórica na ordem $800 \mathrm{~m}^{2} / \mathrm{g}$, elevada capacidade de troca de cátions com possibilidade de reagir com os mais diversos compostos químicos condicionando diferentes comportamentos e finalmente seu baixo custo. A definição do termo 'argila esmectítica' é, por vários autores, 
realizada de forma variada, porém, a essência do termo é aceita por todos. As argilas esmectíticas são geralmente constituídas por partículas cristalinas muito pequenas de um número restrito de minerais conhecidos como argilominerais, podendo ser compostas por partículas de um argilomineral ou por uma mistura de vários argilominerais, esse termo é usado para designar especificamente os filossilicatos que são hidrofílicos e conferem a propriedade de plasticidade às argilas. Os argilominerais são compostos por silicatos lamelares hidratados de alumínio, magnésio e ferro (filossilicatos), contendo ainda, na maioria das vezes, pequenos teores de elementos alcalinos e alcalino terrosos. Além dos argilominerais, as argilas possuem normalmente, outros materiais e minerais tais como "matéria orgânica", sais solúveis e partículas de quartzo, pirita, mica, calcita, dolomita e outros minerais residuais, e podem ter também minerais não cristalinos ou amorfos. $O$ total de componentes que não são argilominerais nas argilas dificilmente é inferior a $10 \%$ em massa. Tais componentes apresentam cores variadas, tais como: branco, cinza, amarelo, marrom, verde e azul [3-7]. Tecnologicamente as argilas esmectíticas são geralmente denominadas bentonitas, podendo ser consideradas como qualquer argila constituída por argilominerais do grupo da esmectita. Geologicamente são apresentadas como uma rocha constituída essencialmente por um ou alguns argilominerais esmectíticos, tendo a montmorilonita como argilomineral predominante, formado pela desvitrificação e subsequente alteração química de um material vítreo, de origem ígnea, usualmente um tufo ou cinza vulcânica, de preferência ácida. Tecnologicamente há um consenso que se argilas esmectíticas apresentarem propriedades análogas às das bentonitas tradicionais e/ou se já forem utilizadas comercialmente para essa finalidade, podem ser denominadas bentonitas, independentemente de sua origem geológica [3, 8-10].

Atualmente, o mercado de bentonita está muito concentrado nos EUA, sendo considerado o maior produtor mundial, contando com elevados investimentos aplicados nessa indústria, o que vem proporcionando diversificação no seu uso e aplicação [11].

As reservas brasileiras de bentonita correspondem

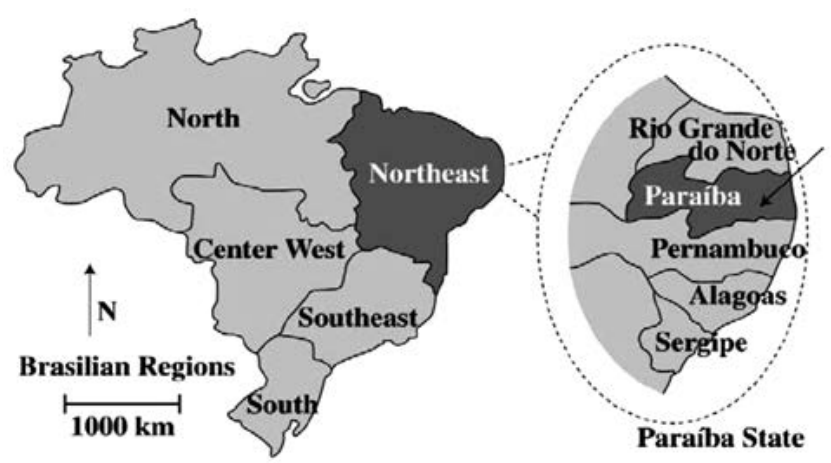

Figura 1: Mapa de localização do estado da Paraíba, Nordeste do Brasil. (Fonte: Silva [12])

[Figure 1: Location map of Paraiba state, Northeast Brazil [12].] aproximadamente a 83 milhões de toneladas, onde os principais depósitos ocorrem nos estados da Paraíba, S. Paulo, Bahia e Piauí, podendo ser encontradas em depósitos relativamente pequenos, onde o mais importante está localizado no nordeste do Brasil, estado da Paraíba, na cidade de Boa Vista. O estado da Paraíba (Fig. 1) é um dos maiores produtores, com cerca de nove empresas, que estão concentradas no município de Boa Vista.

$\mathrm{O}$ consumo dos minerais industriais na indústria de Petróleo no Brasil tem se mantido praticamente inalterado nos últimos anos. No entanto, com a quebra do monopólio do petróleo no País e a entrada de empresas privadas para o setor, espera-se que nos próximos anos haja um aumento de investimentos na exploração e produção de petróleo, o que certamente aumentará a demanda por esses insumos minerais. No Brasil, a produção dos minerais industriais permanece a cargo de pequenos e médios mineradores que geralmente não dispõem de meios para desenvolver projetos de pesquisa que resultem na melhoria de processos e de produtos introduzindo o controle de qualidade nos seus processos de produção [12-14].

Até a década de 60 o Brasil importava toda a bentonita utilizada em fluidos de perfuração. Hoje, as jazidas de Boa Vista, PB, tornam o país praticamente auto-suficiente em argilas bentoníticas, sendo responsável por $88 \%$ de toda a produção de argila bruta, sendo a maior ocorrência conhecida em toda a América do Sul. Atualmente, acumulam aproximadamente 16 milhões de toneladas de bentonita, representando $96,0 \%$ da produção brasileira de argila bruta e beneficiada, sendo $74,0 \%$ deste total produzida na cidade de Campina Grande, PB. Quarenta anos após a sua descoberta, o processo de exploração das jazidas de argilas de Boa Vista, PB, torna-se cada vez mais intenso, bem como sua industrialização, as variedades de melhor qualidade estão se exaurindo $[15,16]$.

Recentemente foram descobertos novos depósitos de bentonitas nas regiões de Cubatí e Pedra Lavrada, PB, criando uma grande expectativa de ampliação da produção mineral na região [13]. Estudos para o desenvolvimento de aplicações industriais estão sendo realizados e aprofundados.

Foram estudadas novas ocorrências de argilas esmectíticas do município de Pedra Lavrada, PB, para uso em fluidos de perfuração base água [17]. Os resultados evidenciaram que as amostras estudadas apresentaram na sua composição mineralógica esmectita, caulinita e quartzo. Em relação às propriedades reológicas verificou-se que as amostras estudadas atenderam parcialmente aos requisitos de viscosidade da norma Petrobrás [18].

Sendo assim, esse trabalho tem como objetivo estudar novos depósitos de argilas esmectíticas do município de Sossego, PB, através da caracterização física, química e mineralógica, como também as propriedades reológicos baseado na norma da Petrobrás para uso em fluidos de perfuração base água. Desta forma, espera-se que através dos resultados de caracterização física e mineralógica desses materiais, seja possível beneficiar e comercializar as bentonitas desses novos depósitos. 


\section{MATERIAIS E MÉTODOS}

Foram estudadas sete amostras de argilas esmectitícas oriundas das novas ocorrências do município de Sossego do estado da Paraíba, fornecida pela empresa DBM Minerais, situada no município de Equador Rio Grande do Norte, RN. As amostras foram denominadas conforme Tabela I.

A caracterização das amostras foi efetuada por meio das seguintes técnicas: difração de raios $\mathrm{X}$ (DRX) (XRD6000 Shimadzu), com radiação Cuka (40 kV/30 $\mathrm{mA}$ ) e velocidade do goniômetro de $2 \% \mathrm{~min}$ com passo de $0,02^{\circ}$, na faixa de $2^{\circ}$ a $60^{\circ}$ para as amostras naturais e com faixa de $2^{\circ}$ a $30^{\circ}$ para as amostras tratadas com etileno glicol; análise termogravimétrica (ATG) e análise térmica diferencial (ATD) (sistema de análise térmica simultânea TA $60 \mathrm{H}$ Shimadzu), com taxa de aquecimento $12,5^{\circ} \mathrm{C} / \mathrm{min}$ sob atmosfera de ar (a temperatura máxima para ambos os casos foi $1000{ }^{\circ} \mathrm{C}$ e o padrão utilizado na ATD foi óxido de alumínio $\left(\mathrm{Al}_{2} \mathrm{O}_{3}\right)$ calcinado); análise granulométrica por espalhamento laser (equipamento Cilas $1064 \mathrm{~L} / \mathrm{D}$ ), e análise química por fluorescência de raios X (EDX 720 Shimadzu).

Tabela I - Identificação e descrição das amostras. [Table I-Identification of the samples and their descriptions.]

\begin{tabular}{cc}
\hline Amostra & Nome Original \\
\hline AM1 & Cinza \\
AM2 & Verde Claro Diel \\
AM3 & Clara ERIVS \\
AM4 & Clara GN2 \\
AM5 & Verde Fernando \\
AM6 & Verde Claro ZP \\
AM7 & Verde Ranufo \\
\hline
\end{tabular}

Após os ensaios de caracterização, as argilas bentoníticas policatiônicas foram transformadas em sódicas, utilizandose soluções concentradas de carbonato de sódio $\left(\mathrm{Na}_{2} \mathrm{CO}_{3}\right)$ nos seguintes teores: $75,100,125,150$ e $175 \mathrm{meq} / 100 \mathrm{~g}$ de argila seca para as amostras. As propriedades reológicas determinadas foram: viscosidade aparente (VA) e viscosidade plástica (VP) em viscosímetro Fann 35A. Volume de filtrado foi analisado em filtro prensa Fann. Todos os ensaios foram determinados de acordo com norma da Petrobrás [18].

\section{RESULTADOS E DISCUSSÃO}

Nas Figs. 2 e 3 estão as curvas de distribuição de tamanho de partículas das amostras estudadas.

As amostras apresentaram curvas distribuição de partículas monomodais e bimodais, nas quais é possível observar uma concentração de partículas entre 3 e $6 \mu \mathrm{m}$. Em relação ao volume acumulado, observou-se em D50 5,28 $\mu \mathrm{m}$ para amostra AM1, 3,83 $\mu \mathrm{m}$ para amostra AM2, 3,75 $\mu \mathrm{m}$ para amostra AM3, 4,95 $\mu \mathrm{m}$ para amostra AM4, 3,06 $\mu \mathrm{m}$ para amostra AM5, 3,04 $\mu \mathrm{m}$ para amostra AM6 e 4,20 $\mu \mathrm{m}$

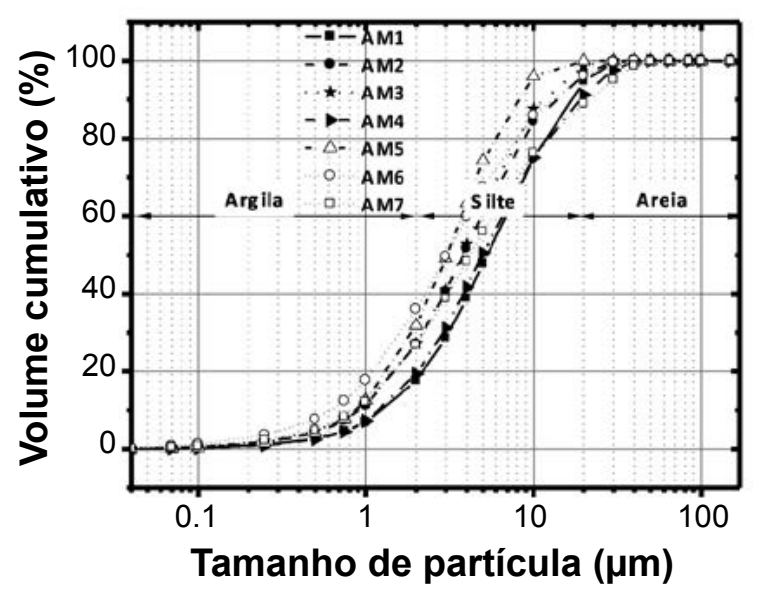

Figura 2: Distribuição granulométrica das argilas estudadas. [Figure 2: Granulometry distribution of the studied clays.]

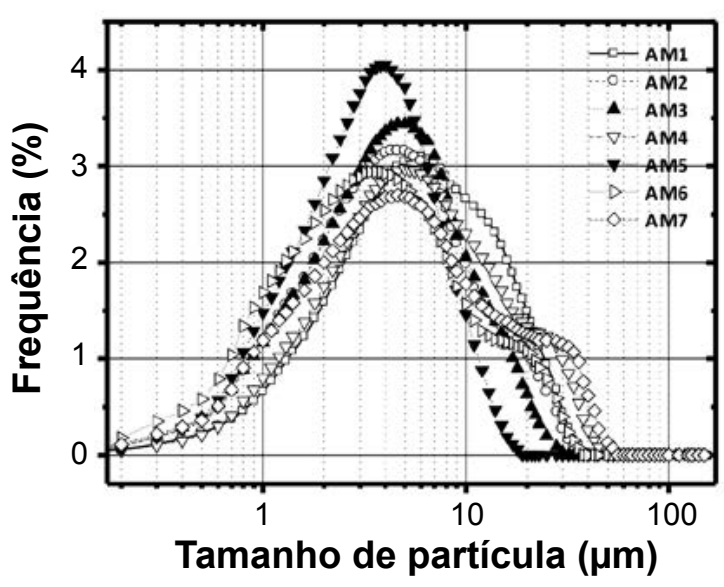

Figura 3: Histograma da distribuição granulométrica das argilas estudadas.

[Figure 3: Histogram of granulometry distribution of the studied clays.]

para amostra AM7.

Na Tabela II estão apresentados os valores da composição granulométrica das amostras estudadas.

As amostras que apresentaram maiores percentuais de volume acumulado da fração argila $(\mathrm{D}<2 \mu \mathrm{m})$ foram AM6 (35,95\%) e AM5 (31,83\%), correspondendo ao menor diâmetro médio de partícula de 3,74 $\mu \mathrm{m}$ e 5,02 $\mu \mathrm{m}$, respectivamente. Em relação aos teores de silte $(2 \mu \mathrm{m}<\mathrm{D}<$ $20 \mu \mathrm{m})$ foram as amostras AM1 $(77,14 \%)$ e AM4 $(71,94 \%)$. Para os teores de areia $(\mathrm{D}>20 \mu \mathrm{m})$ foram às amostras AM4 $(8,72 \%)$ e $\operatorname{AM} 1(5,27 \%)$.

Comparando os resultados de distribuição de tamanho de partículas das amostras em estudo com as argilas bentoníticas de Pedra Lavrada, PB [17], verifica-se que os resultados apresentados são similares, evidenciando assim que provavelmente estas amostras possuem características físicas semelhantes às esmectitas de Pedra Lavrada, PB.

Na Tabela III, estão contidos os valores da composição química das amostras estudadas.

Verifica-se que as amostras apresentaram elevados teores de sílica 51,45\% (AM3) e alumina 27,13\% (AM4); 
Tabela II - Composição granulométrica das argilas estudadas. [Table II - Granulometric composition of the studies clays.]

\begin{tabular}{lcccc}
\hline Amostra & $\begin{array}{c}\text { Argila (\%) } \\
(\mathrm{D}<2 \mu \mathrm{m})\end{array}$ & $\begin{array}{c}\text { Silte }(\%) \\
(2 \mu \mathrm{m}<\mathrm{D}<20 \mu \mathrm{m})\end{array}$ & $\begin{array}{c}\text { Areia (\%) } \\
(\mathrm{D}>20 \mu \mathrm{m})\end{array}$ & $\begin{array}{c}\text { Diâmetro médio } \\
(\mu \mathrm{m})\end{array}$ \\
\hline AM1 & 17,59 & 77,14 & 5,27 & 7,23 \\
AM2 & 26,90 & 69,66 & 3,44 & 5,63 \\
AM3 & 27,22 & 71,67 & 1,11 & 5,03 \\
AM4 & 19,34 & 71,94 & 8,72 & 7,65 \\
AM5 & 31,83 & 68,17 & 0,00 & 3,74 \\
AM6 & 35,95 & 60,10 & 3,95 & 5,02 \\
AM7 & 26,81 & 62,09 & 11,1 & 7,84 \\
\hline
\end{tabular}

essa presença significativa dos teores nas amostras pode ser oriunda da camada tetraédrica e octaédrica dos argilominerais esmectítas e caulinitas, como também dos minerais acessórios [3]. A presença de $\mathrm{Fe}, \mathrm{Mg}$ e outros pode ser decorrente de substituições isomórficas da camada octaédrica da esmectita [9]. Para o teor de $\mathrm{Fe}_{2} \mathrm{O}_{3}$, os valores variaram entre 4 e $7 \%$, que pode ser decorrente da camada octaédrica da esmectita ou de minerais acessórios na forma de hematita [9]. Os teores de ferro em $\sim 7,0 \%$ são típicos das argilas do município de Boa Vista, PB [13, 19, 20]. Os teores de óxido magnésio variaram entre 2 e $3 \%$, o que pode ser provavelmente da camada octaédrica da esmectita ou do carbonato de magnésio. As amostras AM1, AM2 e AM7 apresentaram teores de óxido de cálcio variando entre 4 e $6 \%$, provavelmente do mineral acessória calcita. As amostras apresentaram perda ao fogo entre 10 e $16 \%$, o que está relacionado à perda de águas coordenadas e adsorvidas, hidroxilas dos argilominerais, carbonatos, matéria orgânica e outros. Comparando os valores determinados com as argilas do município de Pedra Lavrada, PB e Cubatí, PB [9,17], verifica-se que as amostras em estudo possuem valores similares às argilas bentoníticas desses municípios.

Nas Figs. 4a e 4b estão representadas as curvas das análises termodiferencial (DTA) e termogravimétrica (TG) das amostras AM1, AM2, AM3, AM4, AM5, AM6 e AM7.

$\mathrm{Na}$ Fig. 4a foram observadas as seguintes transformações térmicas: grande pico endotérmico em $\sim 95^{\circ} \mathrm{C}$, caracterizando a presença de água livre e adsorvida, pico exotérmico entre $95{ }^{\circ} \mathrm{C}$ e $506{ }^{\circ} \mathrm{C}$, correspondente à combustão de matéria orgânica, pico endotérmico em $\sim 506{ }^{\circ} \mathrm{C}$ caracterizando a presença de hidroxilas da folha octaédrica da esmectita e caulinita; para as amostras AM1, AM2, AM3 e AM7 foi observado ainda um pico endotérmico em $\sim 701{ }^{\circ} \mathrm{C}$, possivelmente relacionado a carbonato de magnésio, pico endotérmico com máximo em $900{ }^{\circ} \mathrm{C}$ caracterizando a presença de carbonato de cálcio; estes resultados estão de acordo com a composição química (Tabela III) e pico exotérmico com máximo em $930{ }^{\circ} \mathrm{C}$ característico da nucleação de mulita com liberação de quartzo $\beta$ a partir da estrutura amorfa criada anteriormente. Em relação às curvas de TG (Fig. 4b), observa-se que a perda total de massa variou entre 18 e $23 \%$, correspondente às perdas de água, de matéria orgânica, hidroxilas e carbonatos.

Comparando os resultados dos termogramas com os valores reportados [17] para as argilas de Pedra Lavrada, PB, bem como para as argilas de Cubatí, PB [9, 19], observa-se que são similares, evidenciando um comportamento típico das argilas bentoníticas.

As Figs. 5, 6, 7 e 8 apresentam os difratogramas de raios $\mathrm{X}$ das amostras AM1, AM2, AM3, AM4, AM5, AM6 e AM7 naturais e tratadas com etileno glicol.

Foi comprovada a presença de argilomineral esmectítico para as amostras AM1 e AM2 com adição de etileno glicol, que modificou a distância interplanar basal de 15,6 ̊ para

Tabela III - Composições químicas (\%) das argilas estudadas.

[Table III - Chemical compositions (\%) of the studied clays.]

\begin{tabular}{cccccccc}
\hline Amostras & $\mathrm{SiO}_{2}$ & $\mathrm{Al}_{2} \mathrm{O}_{3}$ & $\mathrm{CaO}$ & $\mathrm{Fe}_{2} \mathrm{O}_{3}$ & $\mathrm{MgO}$ & $\begin{array}{c}\text { Outros } \\
\text { óxidos }\end{array}$ & PF \\
\hline AM1 & 46,14 & 23,53 & 6,57 & 4,73 & 2,69 & 2,01 & 14,31 \\
AM2 & 48,17 & 23,40 & 5,19 & 5,82 & 2,71 & 2,64 & 12,08 \\
AM3 & 51,45 & 23,56 & $\mathrm{NE}$ & 5,93 & 3,44 & 3,57 & 12,05 \\
AM4 & 50,77 & 27,13 & $\mathrm{NE}$ & 5,69 & 2,89 & 2,37 & 11,16 \\
AM5 & 49,74 & 26,40 & $\mathrm{NE}$ & 7,21 & 2,36 & 3,75 & 10,53 \\
AM6 & 48,93 & 23,13 & $\mathrm{NE}$ & 6,34 & 1,99 & 3,03 & 16,57 \\
AM7 & 50,00 & 22,45 & 4,80 & 5,45 & 2,75 & 2,25 & 12,31 \\
\hline PF-Perda ao Fogo; NE-Não Existem. & & & & &
\end{tabular}



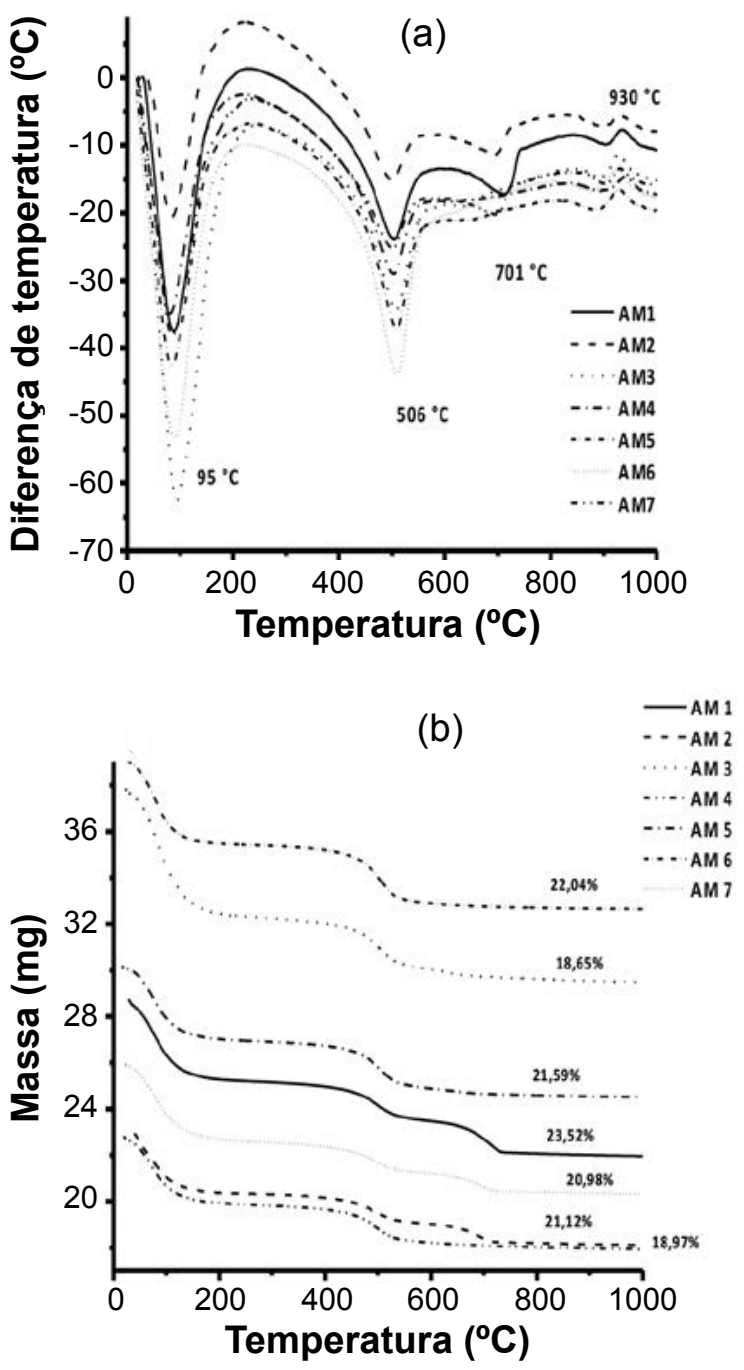

Figura 4: DTA e TG das argilas em estudo: a) DTA, b) TG. [Figure 4: DTA and TG of the studied clays: a) DTA, b) TG.]

$17 \AA$. Também foram observados argilominerais caulinita caracterizado pela distancia interplanar de $7 \AA$ e $3,56 \AA$, feldspato caracterizado pela distância interplanar de $3,77 \AA \mathrm{e}$ $3,02 \AA$ e quartzo caracterizado pelas distâncias interplanares de $4,22 \AA$ e $3,33 \AA$.

Verifica-se a presença do argilomineral esmectítico com a adição de etileno glicol, que modificou a distância interplanar basal de $15 \AA$ para $16,3 \AA$ para $\mathrm{AM} 3$ e de 4,9 $\AA$ para $16,3 \AA$ para AM4. Também foram observados argilominerais caulinita caracterizado pelas distâncias interplanares de 7,11 $\AA$ e $3,57 \AA$, feldspato de $3,22 \AA$ e 3,01 $\AA$ e quartzo de $4,16 \AA$ e $3,33 \AA$.

Os difratogramas de raios $X$ das Figs. 7 a e $7 b$ mostram o argilomineral esmectítico, comprovado com a adição de etileno glicol, que modificou a distância interplanar basal de $15,88 \AA$ para $17 \AA$ para amostra AM5, e de $15,6 \AA$ para 17,4 $\AA$ para amostra AM6. Também foram observados argilominerais caulinita caracterizado pelas distâncias interplanares de $7,11 \AA$ e $3,56 \AA$, feldspato caracterizado pela distância interplanar de $3,22 \AA$ e quartzo caracterizado
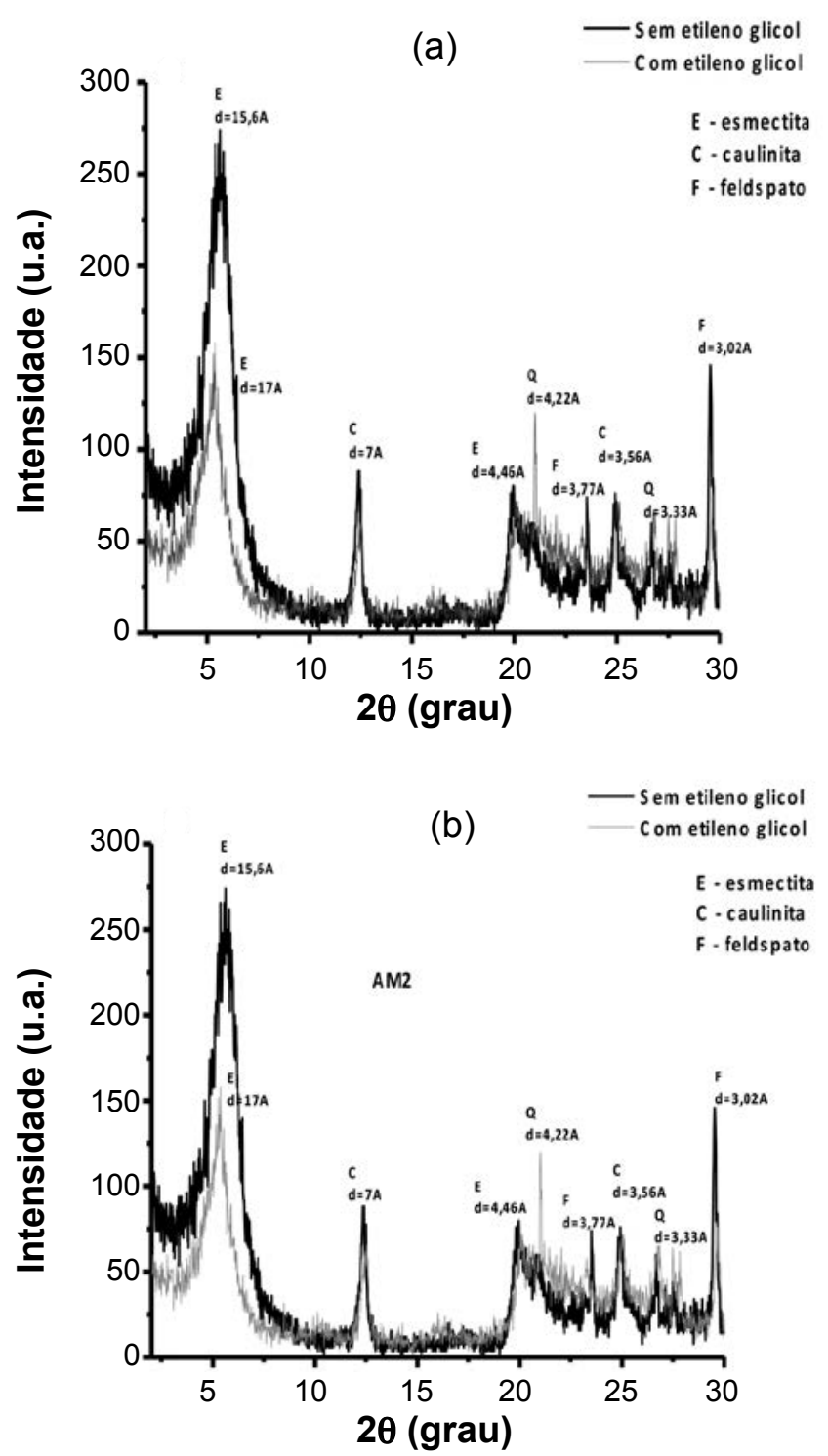

Figura 5: Difratogramas de raios $X$ das argilas naturais e tratadas com etileno glicol.

[Figure 5: XRD patterns of natural and treated with ethylene glycol clays.]

pela distância interplanar de 4,21 Å e 3,33 A.

Os difratogramas de raios $\mathrm{X}$ mostram a presença do argilomineral esmectítico, comprovada com a adição de etileno glicol, que modificou a distância interplanar basal de $15 \AA$ para $16,3 \AA$ para a amostra AM7. Também foram observados argilominerais caulinita caracterizado pela distância interplanar basal de $7,15 \AA$ e $3,56 \AA$, feldspato caracterizado pela distância de interplanar basal de 3,02 $\AA$ e quartzo caracterizado pelas distâncias interplanares de 4,21 $\AA$ e $3,33 \AA$. As argilas bentoníticas do município de Pedra Lavrada, PB, apresentaram as fases mineralógicas esmectita, caulinita e quartzo, sendo esses resultados similares aos das argilas do município de Sossego, PB [17].

Nas Figs. 9 e 10 estão apresentados os resultados de viscosidade aparente, plástica e volume de filtrado das amostras estudadas. 

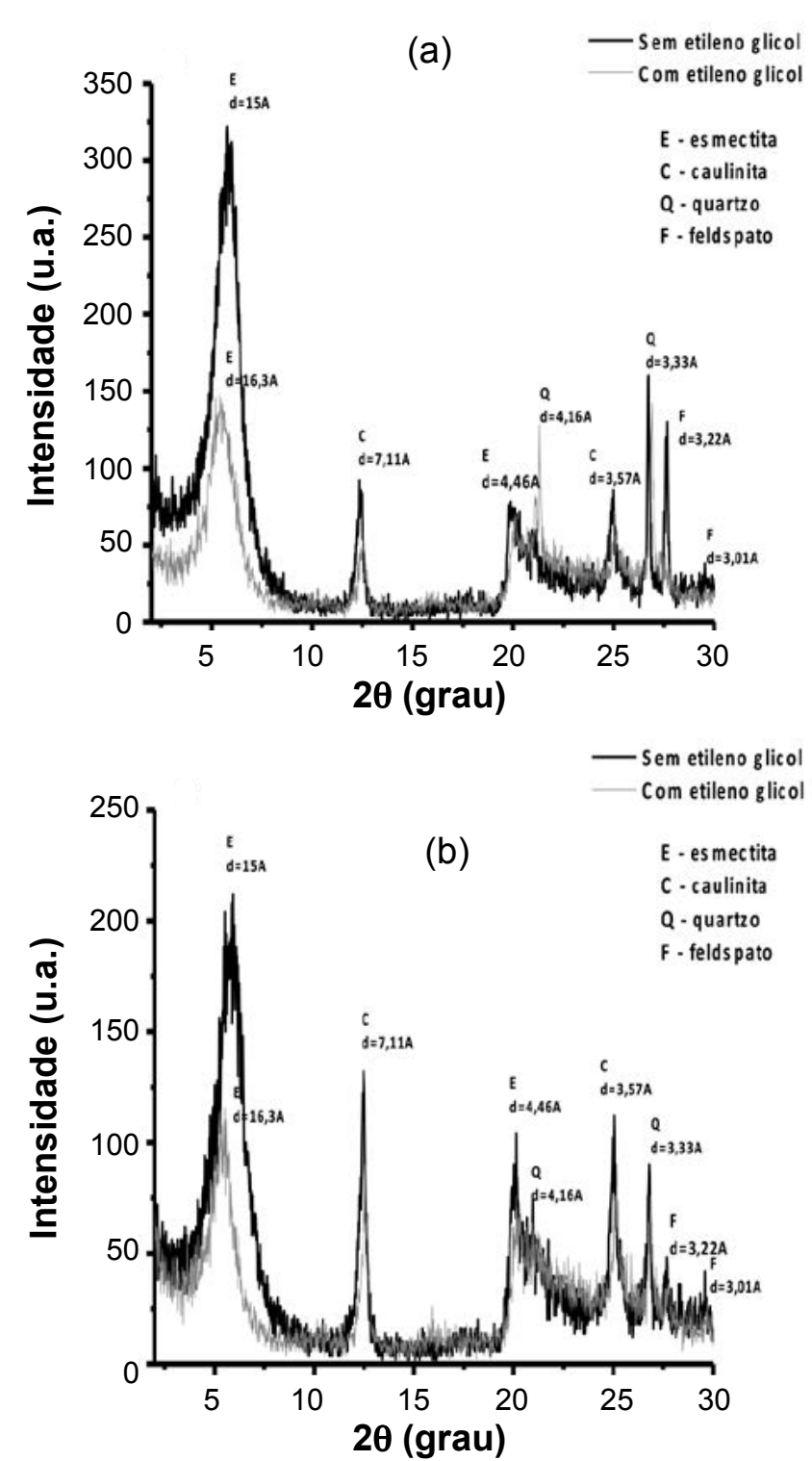

Figura 6: Difratogramas de raios $\mathrm{X}$ das argilas naturais e tratadas com etileno glicol.

[Figure 6: XRD patterns of natural and treated with ethylene glycol clays.]

Verifica-se que as amostras AM3 e AM7 para 75 meq/100g de argila, AM3 e AM4 para 125 meq/100 g, e amostra AM3 para todas aditivações de carbonato de sódio, atingiram valores de viscosidade aparente superior ao máximo especificado pela norma da Petrobrás [18]. Para viscosidade plástica Fig. 9b as amostras AM4 para 100 meq/100 g de argila e AM3 para 100, 125 e $150 \mathrm{meq} / 100$ $\mathrm{g}$ de argila atingiram valores máximo especificados pela norma da Petrobrás [18]. Com relação ao volume de filtrado (Fig. 10), todas as amostras apresentaram valores superiores ao máximo especificado pela Petrobrás que é de $18 \mathrm{~mL}$, com exceção da amostra AM3 com ativação de 125 meq/100 g de argila.

Em uma análise conjunta dos resultados das propriedades reológica apresentadas, verifica-se que as argilas em estudo apresentaram resultados similares e promissores
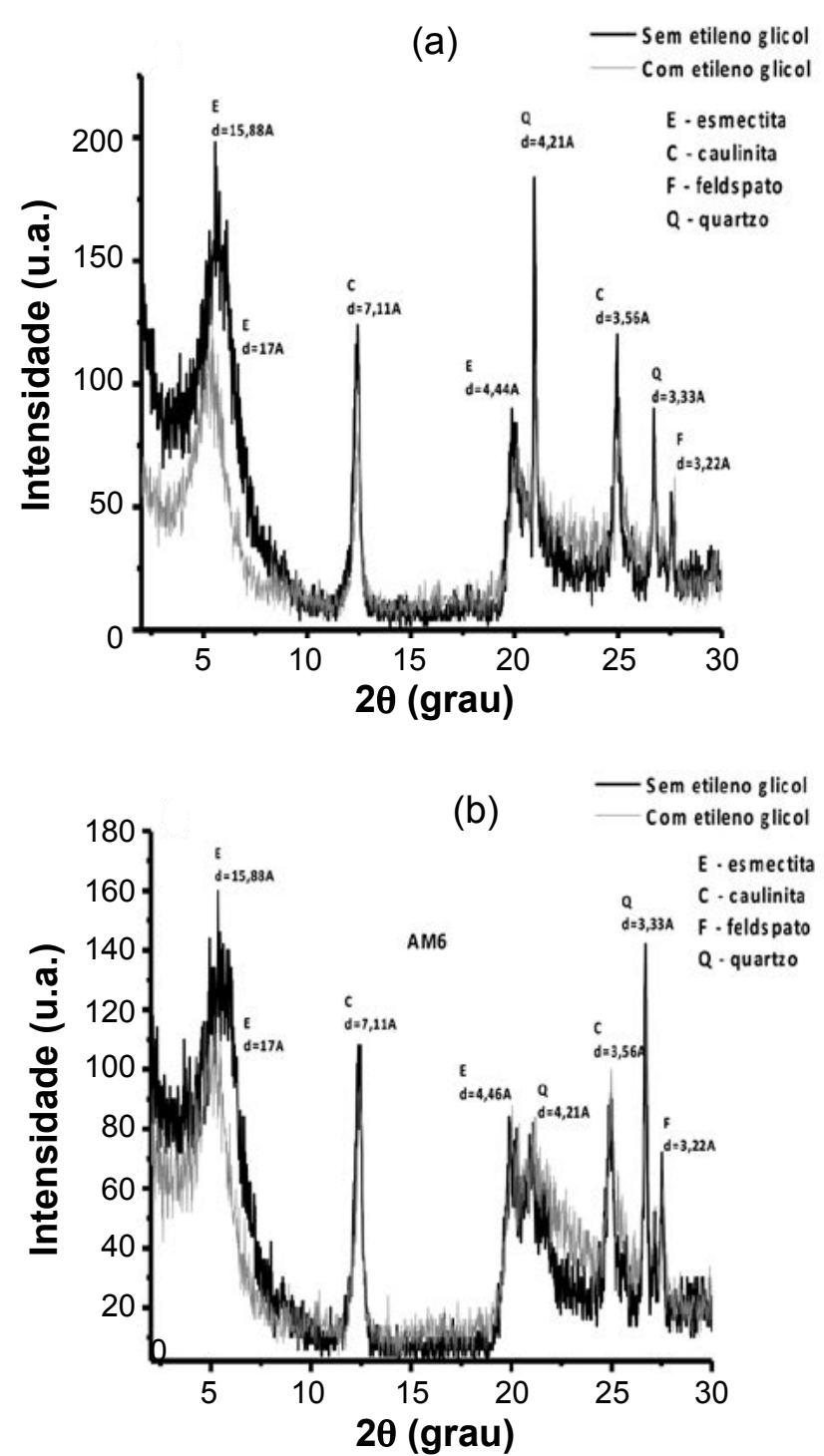

Figura 7: Difratogramas de raios $\mathrm{X}$ das argilas naturais e tratadas com etileno glicol.

[Figure 7: XRD patterns of natural and treated with ethylene glycol clays.]

para aplicação tecnológica, principalmente em fluidos de perfuração de poços, entretanto, deve salientar que estudos mais detalhados são necessários para viabilizar seu uso tecnológico. Segundo estudo [16], resultados animadores comprovaram que, com a adição de aditivos industriais existem prováveis respostas sobre o estado floculado-gel das dispersões de argilas, como: elevação da viscosidade aparente, plástica, redução do volume do filtrado, estabilização do $\mathrm{pH}$ e umidade podem ser conseguidas a modo de se alcançar os requisitos estabelecidos pela norma.

No estudo de argilas provenientes da região da Paraíba, principalmente do município de Pedra Lavrada, foram alcançados resultados semelhantes, sendo afirmado que esse fato pode ser atribuído à presença de quartzo nas argilas, porém a elevada quantidade de caulinita nas argilas também é um fator que influencia nas propriedades reológicas dos 


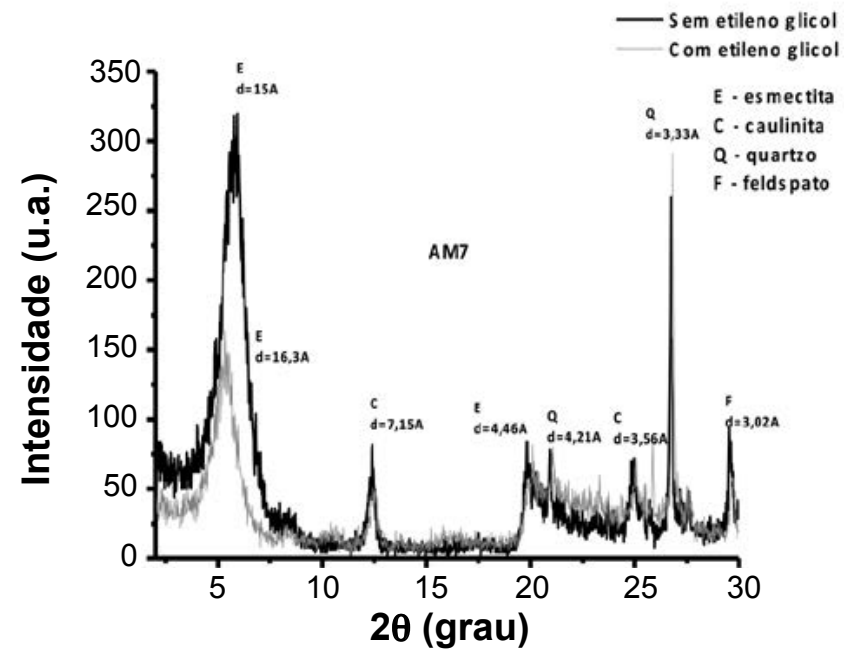

Figura 8: Difratogramas de raios $\mathrm{X}$ das argilas naturais e tratadas com etileno glicol.

[Figure 8: XRD patterns of natural and treated with ethylene glycol clays.]
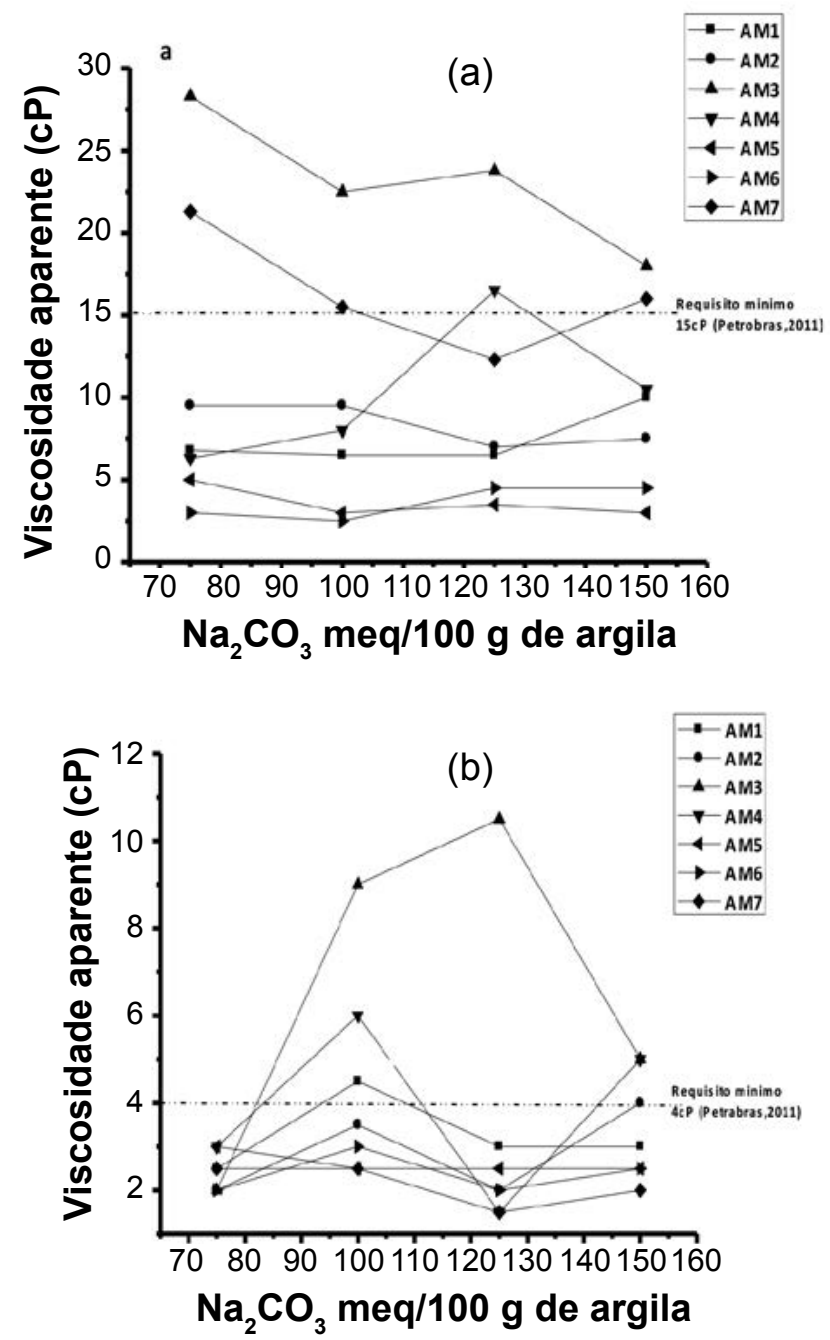

Figura 9: Viscosidade aparente (a) e plástica (b) das argilas estudadas.

[Figure 9: Apparent (a) and plastic (b) viscosity of the studied clays.]

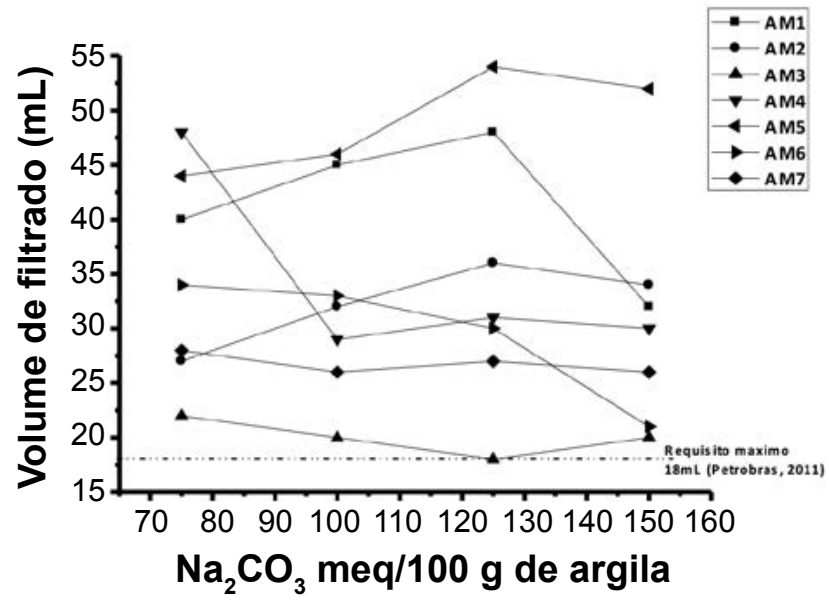

Figura 10: Volume de filtrado das argilas estudadas.

[Figure 10: Filtered volume of the studied clays.]

fluidos base água [7,17]; segundo esses autores os resultados obtidos nesse estudo não podem ser generalizados para todo o depósito em estudo, para isso seria necessário um mapeamento geológico da região para que pudesse analisar as variações que ocorrem nas camadas ao longo do perfil geológico, fator observado também por outros autores [1], onde se afirma que em um depósito de argila a natureza da mistura de minerais e a composição dos minerais argilosos individuais podem variar radicalmente em uma extensão de poucos centímetros; conseqüentemente, qualquer depósito pode conter muitos tipos de argila sutilmente diferentes.

\section{CONCLUSÕES}

A partir dos estudos de novas ocorrências de argilas esmectíticas do município de Sossego, PB, pode-se concluir que as amostras apresentaram na sua composição mineralógica esmectita, caulinita e quartzo. Em relação às propriedades reológicas, verificou-se que as amostras atendem parcialmente as especificações das normas da Petrobrás para uso em fluidos de perfuração base água, e que a amostra AM3 (Clara ERIVS) é a mais promissora.

\section{REFERÊNCIAS}

[1] E. Teixeira-Neto, A. A. Teixeira-Neto, Quim. Nova 32, 3 (2009) 809-817.

[2] C. Karagüzel, T. Çetinel, F. Boylu, K. Çinku, M. S. Çelik, Appl. Clay Sci. 48 (2010) 398-404.

[3] P. Souza Santos, Ciência e Tecnologia de Argilas, $3^{\mathrm{a}}$ Ed., Vol. 1, Edgard Blücher, S. Paulo, SP (1992).

[4] D. Zhang, C. H. Zhou, C. X. Lin, D. S. Tong, W. H .Yu, Appl. Clay Sci. 50 (2010) 1-11.

[5] J. P. P. Porto, I. B. Aranha, Anais da JIC (2010).

[6] D. M. Fermino, Estudo das propriedades mecânicas, reológicas e térmicas de nanocompósito de hmspp (polipropileno com alta resistência do fundido) com uma bentonita brasileira, Diss. Mestrado, IPEN, SP (2011).

[7] D. A. Tonnesen, L. C. Bertolino, A. B. Luz, F. T. Silva, 
D. M. Timóteo, Holos 1 (2012).

[8] A. R. V. Silva, H. C. Ferreira, Rev. Eletr. Mater. Proc. 3, 2 (2008) 26-35.

[9] R. R. Menezes, P. M. Souto, L. N. L. Santana, G. A. Neves, R. H. G. A. Kiminami, H. C. Ferreira, Cerâmica 55, 334 (2009) 163-169.

[10] T. Kameda, S. Shimamori, T. Yoshioka, J. Phys. Chem. Solids 73 (2012) 120-123.

[11] DNPM, Departamento Nacional Pesquisa Mineral, Anuário Mineral Brasileiro (2012).

[12] M. M. sSilva, A. C. L. Patrício, W. S. Lima, H. M. Laborde, M. G. F. Rodrigues, Scientia Plena 7 (2011) 9.

[13] C. Bertagnolli, M. G. C. Silva, Mater. Res. 15, 2 (2012) 253-259.

[14] A. B. Luz, C. A. M. Baltar, Insumos minerais para a perfuração de poços de petróleo, CETEM/UFPE 102 (2003).

[15] L. F. A. Campos, Composições de argilas bentoníticas para utilização em fluidos de perfuração de poços de petróleo, Tese Dr., Eng. Proc. CCT, UFCG, PB (2007).

[16] L. V. Amorim, Melhoria, proteção e recuperação da reologia de fluidos hidroargilosos para uso na perfuração de poços de petróleo, Tese Dr., Eng. Proc. CCT, UFCG, PB (2003).

[17] I. A. Silva, J. M. R. Costa, R. R. Menezes, H. S. Ferreira, G. A. Neves, H. C. Ferreira, Rev. Esc. Minas 66, 4 (2013) 485-491.

[18] Petrobrás, Ensaio de viscosificante para fluidos base água na exploração e produção de petróleo, Código:EP1EP-00011-A (2011).

[19] A. P. S. Batista, R. R. Menezes, L. N. Marques, L. A. Campos, G. A. Neves, H. C. Ferreira, Rev. Eletr. Mater. Proc. 4, 3 (2009) 64-71.

[20] H. S. Ferreira, L. F. A. Campos, R. R. Menezes, J. M. Cartaxo, L. N. L. Santana, G. A. Neves, H. C. Ferreira, Cerâmica 59, 350 (2013) 277-284.

(Rec. 18/12/2012, Rev. 26/12/2012, Ac. 02/01/2014) 